\title{
A rare complication seen in a child diagnosed with acute lymphoblastic leukemia: Isolated penile gangrene
}

\author{
Chauhan $\mathbf{R}^{1}$, Singh $\mathbf{G}^{2}$, Singh U.P ${ }^{3}$ \\ ${ }^{1}$ Dr Richa Chauhan, Consultant, Radiation Oncologist, Mahavir Cancer Sansthan, Patna, ${ }^{2}$ Dr Gyanendra Singh, Resident \\ Surgeon, Sanjeevani Hospital, Patna, ${ }^{3}$ Dr U.P Singh, Consultant Surgeon \& Director, Sanjeevani Hospital, Patna, Bihar, \\ India.
}

Address for Correspondence: Dr Richa Chauhan, Email: chauhan_richa@outlook.com

\begin{abstract}
Leukemia is the most common cancer seen in children with acute lymphoblastic leukemia, accounting for $80 \%$ of all childhood leukemias and $24 \%$ of all cancers in children. The intensive chemotherapy regimen used in the treatment is often associated with a number of complications. Thromboembolic events in the form of coagulopathy and thrombosis have been reported in patients of acute leukemia undergoing chemotherapy. In the present study, we report the case of a 10 -year-old boy with acute lymphoblastic leukemia (ALL) who developed dry gangrene of the penis while on chemotherapy. Dry gangrene of the penis is a rare complication, in view of the presence of extensive collateral circulation in the region. This presentation may be correlated to a rare thrombotic complication, associated with hypercoagulable status seen in leukemic patients undergoing chemotherapy.
\end{abstract}

Key words: Leukemia, Thromboembolic events, penile gangrene

\section{Introduction}

Leukemia is the most common cancer seen in children with acute lymphoblastic leukemia, accounting for $80 \%$ of all childhood leukemias and $24 \%$ of all cancers in children. With intensive chemotherapy and allogenic peripheral blood stem cell transplant, the cure rate approaches nearly $80 \%$. However, this intensive treatment is also associated with a number of complications [1]. Thromboembolic events in the form of coagulopathy and thrombosis have been reported in patients of acute leukemia undergoing chemotherapy [2]. The pathogenesis of thrombosis in leukemia patients is not fully understood, but includes a combination of variables related to the disease itself, its treatment, and the host [3]. Most of the reported thrombosis events are venous thrombosis related to central venous catheter [4]. In the present study, we report the case of a child with acute lymphoblastic leukemia (ALL) who developed dry gangrene of the penis while on chemotherapy. Though isolated penile gangrene in a child is a rare complication, a hypercoagulable state leading to thrombosis of penile arteries could be the probable cause.

\section{Case Report}

A 10 year old boy presented with painless, black discolouration of the entire penis. He also complained of urine dribbling from an opening at the root of the penis. The boy was apparently well about 8 months back, when he complained of mild fever, cough and weakness for 1 week. A local physician was consulted and he was started on antibiotics. Laboratory investigations showed a raised total leucocyte count with few atypical cells and decreased haemoglobin. Chest x-ray was normal. Though the fever subsided on antibiotics, a total leucocyte count done after 1 week showed a total count of $1,33,000 / \mathrm{mm}^{3}$ with $89 \%$ blast cells in the peripheral blood. Then the patient was referred to a cancer centre. A bone marrow examination was done and it showed $93 \%$ blast cells, which was followed by immunophenotyping study and the

Manuscript received $14^{\text {th }}$ August 2016

Reviewed: $25^{\text {th }}$ August 2016

Author Corrected: $5^{\text {th }}$ September 2016

Accepted for Publication $19^{\text {th }}$ September 2016 
patient was diagnosed as a case of B cell ALL. Cytogenetic study showed a normal karyotype. RT-PCR was negative for bcr-abl. CSF examination was normal. He was classified as an intermediate risk B- cell ALL and was started on BFM 95 induction chemotherapy. He was started on pre-induction chemotherapy with steroids and was given intrathecal methotrexate. The day 8 steroid response was poor and the patient was further given first dose of Daunorubicin, Vincristine and L-Asparaginase. In view of poor steroid response, the parents were advised for high dose chemotherapy followed by allogenic peripheral blood stem cell transplant. However, the parents decided to continue treatment at their native place due to financial constraints. As the boy became asymptomatic, he defaulted treatment for two months after which he again developed fever, cough and weakness. He then consulted a local oncologist and was advised a complete blood count. Laboratory investigations showed a total leucocyte count of $2400 / \mathrm{mm} 3$, platelet count of $79,000 / \mathrm{mm} 3$ and haemoglobin level of $3.5 \mathrm{gm} / \mathrm{dl}$; chest $\mathrm{x}$ - ray was normal. He was put on antibiotics with blood and platelet transfusion.

Bone marrow examination showed 63\% blast cells. He was then given Cyclophosphamide, Adriamycin, Vincristine, intrathecal methotrexate with dexamethasone and his symptoms subsided. After two months, while still on chemotherapy, he developed pain and swelling of penis with mild fever which subsided after four days. Then the penile swelling started subsiding with black discolouration of the overlying skin. The fever and pain subsided completely in four days. The black discolouration progressed to involve the entire penis and the patient started to pass urine from an opening at the root of the penis. On examination, the entire penis showed features of dry gangrene. (Fig. 1) Total penectomy with refashioning of the urethra was done under general anesthesia, there was no bleeding at the site of amputation and the wound healed well. (Fig. 2 ) The patient recovered well and was referred back to the treating oncologist for continuing chemotherapy.

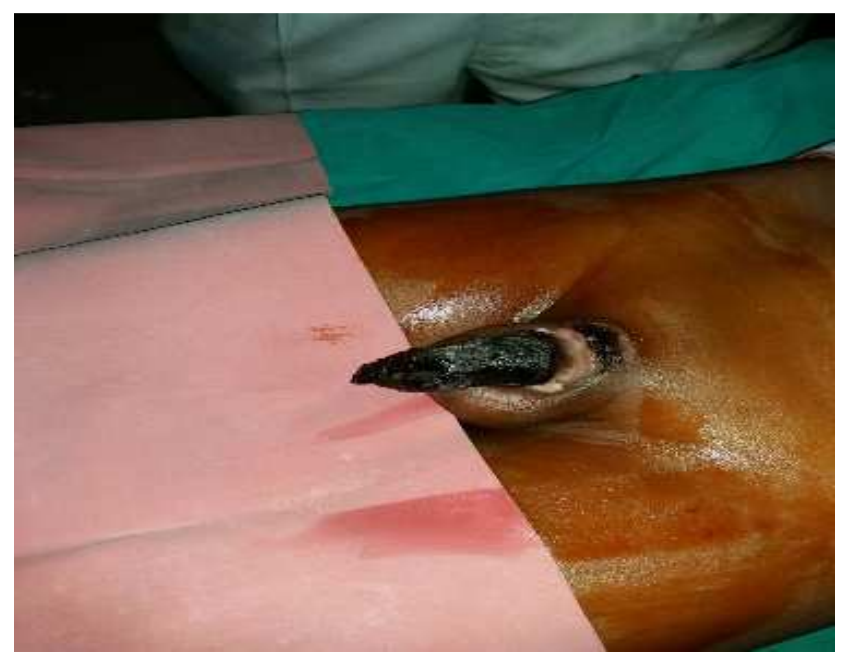

Figure-1: Picture showing total gangrene of the penis

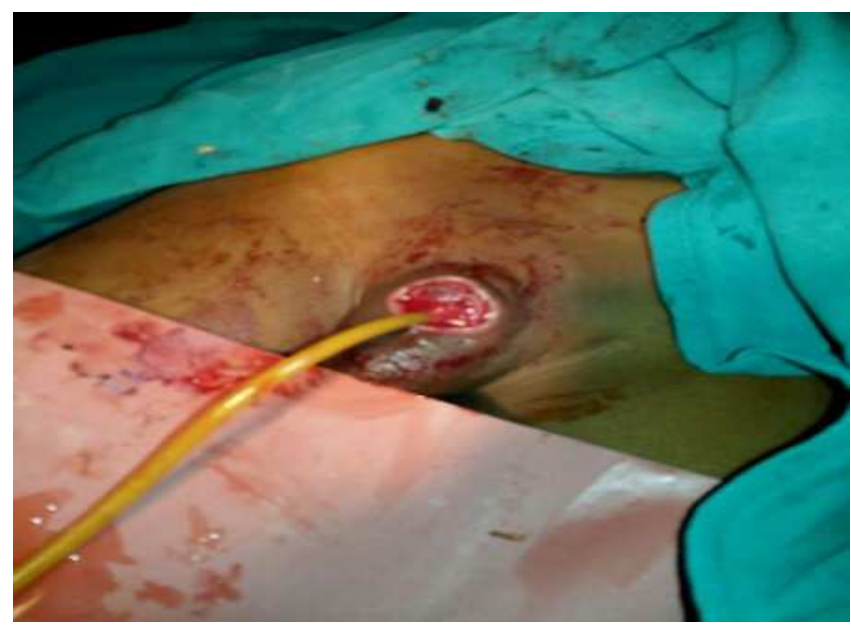

Figure-2: Picture showing total penectomy 


\section{Discussion}

Leukemia is the most common cancer seen in children with acute lymphoblastic leukemia, accounting for $80 \%$ of all childhood leukemias and $24 \%$ of all cancers in children. ALL results from a clonal expansion of dysregulated, immature lymphoid cells and B- precursor leukemias accounts for $85 \%$ of ALL cases in children. [1].

Gangrene in a leukemia patient is seen rarely, but is associated with significant morbidity and mortality. It is further divided into dry or wet gangrene, based on different clinical presentations and pathogenesis. Wet gangrenes are caused by infections and dry gangrenes are usually due to arterial obstruction. Wet gangrene of the genitalia is also called as Fournier's gangrene and is associated with synergistic necrotizing infection of skin or gastro intestinal tract. Foul, feculent odour with crepitus is the classical finding with a raised total count in such patients. Fournier gangrene requires prompt intervention because if left untreated, it rapidly causes progressive tissue destruction, sepsis and ultimately death [5]. The most common cause of vasculogenic or dry gangrene is diabetes mellitus with end-stage renal disease. Ischemic gangrene of male genitalia is a hallmark of severe systemic vascular disease [6]. Few cases of gangrene associated with haematological malignancies have been reported, but most of them were cases of Fournier's gangrene associated with acute myeloid leukemia (AML) [5] Dry gangrene in cancer patients have been reported to develop as a result of calciphylaxis, or calcific uremic arteriolopathy [7]. The other causes of dry gangrene causing necrosis include thromboembolic disease, priapism, paraphimosis, primary hyperparathyroidism, connective tissue diseases and hyper coagulopathy secondary to malignancy [8].

Further, dry gangrene of the penis is rarely seen because of the presence of extensive collateral circulation in the region. Blood supply to the skin of the penis is from the left and right superficial external pudendal arteries, which is a branch of the femoral artery. The blood supply to the ventral penile skin is from the posterior scrotal artery, a superficial branch of the deep internal pudendal artery. The deeper structures of the penis are supplied from three branches of the internal pudendal artery, the bulbourethral artery, the dorsal artery, and the cavernosal artery. The terminal branches of the dorsal artery supply the glans penis. To the best of our search isolated dry gangrene of penis in a case of acute lymphoblastic leukemia has not been reported till date [9].

The possible cause could have been arterial occlusion because of hypercoagulopathy and thrombosis formation. The prevalence and the pathogenesis of thrombosis associated with ALL are obscure. The primary disease itself can activate blood coagulation via procoagulant substances or by impairment of fibrinolytic or anticoagulant pathways. Additionally, chemotherapy, and prothrombotic risk factors of the host might play a contributory role. Thrombotic events have been mainly reported in the central nervous system and in the upper limbs [4].

Thrombosis and coagulopathy are well known adverse effects of induction therapy with L-Asparaginase. It causes inhibition of protein synthesis, which leads to the depletion of other plasma proteins, involved in coagulation and fibrinolysis [10]. Vicarioto et al reported a significant decrease in the plasma fibrinogen and AT-III level in the first two weeks of induction chemotherapy in 20 pediatric ALL patients [11].

Hyperlipidemia is also a known risk factor for thrombosis, and this effect is significantly higher when the patient is also receiving L-Asparaginase and steroid therapy [12].

Abbott et al reported a higher number of ALL children from Asia developing central nervous system thrombus, though it was not statistically significant. They suggested that race might be a predisposing risk factor for thrombosis associated with L-Asparaginase therapy because of inherited polymorphism [13].

\section{Conclusion}

Isolated penile gangrene of the penis in a pediatric patient of acute lymphoblastic leukemia is a rare clinical finding as the organ has a very rich blood supply with collaterals. The induction treatment of ALL may have been the predisposing factor in the development of thrombosis related arterial occlusion leading to dry gangrene of penis seen in this patient. However, a combination of other factors like the disease itself, some acquired conditions or the genetic background could not be ruled out.

Funding: Nil, Conflict of interest: None initiated, Permission from IRB: Yes 


\section{References}

1. Redaelli A, Laskin BL, Stephens JM, Botteman MF, Pashos CL. A systematic literature review of the clinical and epidemiological burden of acute lymphoblastic leukaemia (ALL). Eur J Cancer Care (Engl). 2005 Mar; 14 (1) : 53-62. DOI : 10. $1111 / \mathrm{j}$. 1365-2354. 2005.00513.x

2. Athale, U.H. \& Chan, A.K. (2003a) Thrombosis in children with acute lymphoblastic leukemia: part I. Epidemiology of thrombosis in children with acute lymphoblastic leukemia. Thromb Res. 2003;111 (3): 125-31. Review. PMID:14678808

3. Athale U.H. \& Chan AKC. Thrombosis in children with acute lymphoblastic leukemia: pathogenesis of thrombosis in children with acute lymphoblastic leukemia: effect of the disease and therapy. Thrombosis Res. 2003; 111: 199-212.

4. Payne JH, Vora AJ. Thrombosis and acute lymphoblastic leukemia. $\mathrm{Br}$ J Haematol. 2007 Aug;138(4):430-45. Epub 2007 Jun 29. Review. PMID:17608766

5. D'Arena G, Pietrantuono G, Buccino E, Pacifico G, Musto P. Fournier's Gangrene Complicating Hematologic Malignancies: a Case Report and Review of Literature. Mediterr J Hematol Infect Dis. 2013 Nov 1; 5 (1) : e2013067. doi: 10. 4084 / MJHID. 2013.067. eCollection 2013.

6. Harris C.F \& Mydlo JH. Ischemia and gangrene of the penis. J Urol. 2003 May;169(5):1795. DOI: 10. 1097/01. ju.0000057796.64080.3a.

7. Karpman E, Das S, Kurzrock EA. Penile calciphylaxis: analysis of risk factors and mortality. J
Urol. 2003 Jun; 169(6):2206-9. DOI: 10.1097/01.ju. 0000064334.85656.a1

8. Nigwekar SU, Wolf M, Sterns RH, Hix JK. Calciphylaxis from Nonuremic Causes: A Systematic Review. Clin J Am Soc Nephrol. 2008 Jul;3(4):113943. doi: 10. 2215/CJN.00530108. Epub 2008 Apr 16. Review.

9. Juskiewenski, S., Vaysse, P., Moscovici, J. et al. A study of the arterial blood supply to the penis. Anat. Clin (1982) 4: 101. doi:10.1007/BF01800618.

10. Feinberg WM, Swenson MR. Cerebrovascular complications of L- Asparaginase therapy. Neurology. 1988 Jan; 38(1):127-33. PMID: 3275903

11. Vicarioto M, Rosolen A, Cappellato MG, Zanesco L, Girolami A. Greater decrease of fibrinogen as compared to antithrombin III in L-asparaginase treated leukemia patients. Folia Haematol Int Mag Klin Morphol Blutforsch. 1986; 113(5) : 663-9. PMID: 2435632.

12. Parsons SK, Skapek SX, Neufeld EJ, Kuhlman C, Young ML, Donnelly $\mathrm{M}$ et al. Asparaginase-associated lipid abnormalities in children with acute lymphoblastic leukemia. Blood. 1997 Mar 15; 89(6):1886-95. PMID: 9058708 .

13. Abbott LS, Deevska M, Fernandez CV, Dix D, Price VE, Wang $\mathrm{H}$ et al. The impact of prophylactic fresh-frozen plasma and cryoprecipitate on the incidence of central nervous system thrombosis and hemorrhage in children with acute lymphoblastic leukemia receiving asparaginase. Blood. 2009 Dec 10; 114(25):5146-51. doi: 10.1182/blood-2009-07-231084.

\section{How to cite this article?}

Chauhan R, Singh G, Singh U.P. A rare complication seen in a child diagnosed with acute lymphoblastic leukemia: Isolated penile gangrene.Int J Med Res Rev 2016;4(9):1628-1631.doi:10.17511/ijmrr. 2016.i09.19. 